UDC 81'42:070

Submitted: 22.05 .2018

LBC 81.055.1.5

Accepted: 18.06 .2018

\title{
REPRESENTATION OF RUSSIA'S IMAGE IN GERMAN MEDIA DISCOURSE IN THE CONTEXT OF THE 2018 FIFA WORLD CUP
}

\author{
Marina V. Milovanova \\ Volgograd State University, Volgograd, Russia \\ Marina Yu. Svinkina \\ Volgograd State University, Volgograd, Russia
}

\begin{abstract}
The paper reveals the specifics of constructing the image of Russia in the German media discourse in current media texts covering preparation for the FIFA World Cup, which has been held for the first time on the territory of the Russian Federation. International events of this magnitude put the host country in the center of attention of the world community not only during the event, but long before it, and after the implementation of the project. At the same time, the contact of most members of society with the surrounding reality is mediated by mass communication. In the process of describing the events taking place in Russia, the German media tend to implement the opposition 'own vs. alien'. With the use of lexicographic data, the semantic content of the concept 'own vs. alien' is analyzed, which allows to identify the key aspects of the values underlying this opposition: 'own' and 'alien' denote belongingness, indicate the type and mode of action. The linguistic mechanisms of constructing the image of Russia are characterized. Having analyzed the empiric material, we conclude that the most dominating strategies are alienation and exotization. The main language means for constructing the image of Russia are lexemes with pejorative connotation, culture-specific words, illocutive verbs, comparison.

Key words: media discourse, opposition 'own vs. alien', communicative strategy, foreignization strategy, communicative tactics, reputational capital of the country.

Citation. Milovanova M.V., Svinkina M.Yu. Representation of Russia's Image in German Media Discourse in the Context of the 2018 FIFA World Cup. Vestnik Volgogradskogo gosudarstvennogo universiteta. Seriya 2, Yazykoznanie [Science Journal of Volgograd State University. Linguistics], 2018, vol. 17, no. 3, pp. 148-157. (in Russian). DOI: https://doi.org/10.15688/jvolsu2.2018.3.15
\end{abstract}

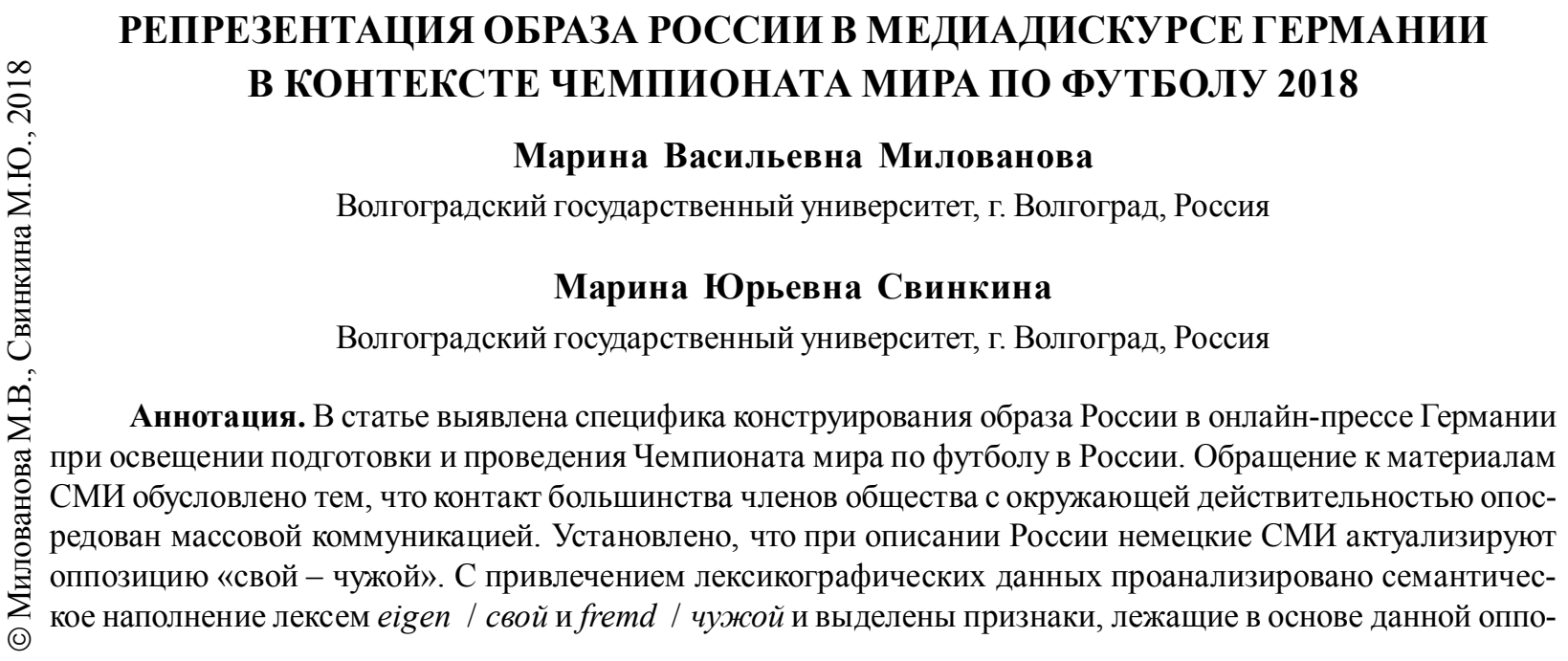


зиции: принадлежность, вид и образ действия. Охарактеризованы языковые механизмы объективации образа России у инокультурного реципиента по мере его знакомства с публикациями о нашей стране и ее жителях. В результате изучения эмпирического материала методом количественного и качественного тематического контент-анализа выявлена востребованность форенизирующих стратегий алиенации и экзотизации, которые реализованы тактиками противопоставления, угрозы, демонизации и аномализации, выделения этноспецифики. Основными вербальными средствами конструирования образа России выступают лексемы с отрицательно-оценочным значением, транскрибированнные лексемы, реалии, иллокутивные глаголы и императивные конструкции, используются приемы сравнения, метафоры, аллюзии, апелляции к стереотипу.

Ключевые слова: медиадискурс, оппозиция «свой - чужой», коммуникативная стратегия, форенизирующая стратегия, коммуникативная тактика, репутационный капитал страны.

Цитирование. Милованова М. В., Свинкина М. Ю. Репрезентация образа России в медиадискурсе Германии в контексте Чемпионата мира по футболу 2018 // Вестник Волгоградского государственного университета. Серия 2, Языкознание. - 2018. - Т. 17, № 3. - С. 148-157. - DOI: https://doi.org/10.15688/jvolsu2.2018.3.15

\section{Введение}

Начиная с декабря 2010 г., когда FIFA было объявлено решение относительно страны-организатора Чемпионата мира по футболу 2018 г., Россия оказалась в фокусе особо пристального внимания зарубежной общественности. Футбол, несомненно, является самым популярным массовым видом спорта, насчитывающим миллионы фанатов во всех частях света. При этом атмосфера спортивного праздника в формате Чемпионата мира строится не только на соревновательном духе, азарте болельщиков, но и на впечатлениях от организации турнира в целом, гостеприимстве хозяев. Идеологической основой организации ЧМ в России стала программа «Стратегическое видение», направленная на выполнение четырех базовых задач: раскрытие позитивного образа России, развитие регионов и создание устойчивого наследия, проведение праздника для футбольного сообщества «от всей души» и популяризация здорового образа жизни.

Решая первую задачу, принимающая сторона стремилась привлечь как можно больше зрителей-иностранцев с целью улучшения современного имиджа России посредством трансляции полученного фанатами личного опыта соотечественникам.

Однако образ другой страны формируется в сознании туристов и до ее посещения, поскольку восприятие реальности людьми осуществляется во многом через СМИ, которые по-своему преломляют информацию. Основная цель массмедиа - отражение действительности, но передача информации - это не констатация фактов объективной реальности, а их интерпретация, то есть создание реальности информационной. Благодаря СМИ некое пространство смыслов для потребителя информации выглядит как реальное. Массмедиа направляют мыслительные процессы и эмоциональные состояния. По мнению немецкого философа, социолога и культуролога Г. Маркузе, именно СМИ активно распространяют модель так называемого одномерного поведения, когда идеи, побуждения и цели, которые не вписываются в «общепринятые» рамки, навязываемые новостной индустрией, либо отторгаются, либо подгоняются под общие стандарты. Данная стратегия лежит, например, в основе создания «массовых психозов». Постоянное упоминание одной и той же информации в массмедиа закрепляет в сознании читателей те или иные стереотипы, притупляя рассудок и воздействуя на бессознательные механизмы. В результате повторов некоторой информации в СМИ человек оказывается словно запрограммированным: он так часто слышит определенный посыл, что начинает считать свои действия актом доброй воли [Маркузе, 1994, с. 82].

Возможность СМИ оказывать влияние на сознание и поведение потребителей транслируемой информации обусловливает многолетний академический интерес к исследованию медиадискурса (М.Р. Желтухина, В.И. Карасик, А.А. Кибрик, Е.И. Шейгал и др.).

Общее определение понятия «медиадискурс» дает Т.Г. Добросклонская: это совокупность процессов и продуктов речевой деятельности в сфере массовой коммуникации во всем богатстве и сложности их взаимодействия. Опираясь на коммуникационную мо- 
дель К. Шэннона и У. Уивера, исследователь делает вывод о том, что текст - это сообщение, медиатекст - это сообщение плюс канал связи, а медиадискурс - это сообщение в совокупности со всеми прочими компонентами коммуникации [Добросклонская, 2012, с. 741]. По мнению Н.Ф. Алефиренко, медиадискурс является одновременно формообразующим и смыслогенерирующим источником вторичного семиозиса. В результате лингвокреативных преобразований смысловых конституентов медиадискурса для образования знаков вторичной номинации порождается национальноязыковое видение картины мира [Алефиренко, 2016, с. 55].

М.Р. Желтухина отмечает, что исследование медиадискурса русской, немецкой, английской или других лингвокультур позволяет увидеть доминирование ценностей над фактами, интенсификацию эмоций, преобладание воздействия и оценки над информированием, эмоционального над рациональным [Желтухина, 2017, с. 138].

Медиатексты концентрируют в себе информацию о текущих событиях, отобранных и интерпретированных в соответствии с авторскими установками, направленностью издания и социально-политическим контекстом, составляющих в целом «повестку дня».

В социополитическом аспекте функционирования языка одним из базовых направлений формирования реальности посредством медиадискурса является создание образов стран и национальных лидеров. Образ представляет собой во многом психологический феномен, однако он нуждается в толковании, вербализации и, следовательно, становится предметом интереса семиотики и лингвистики.

В фокусе настоящего исследования находится специфика конструирования образа России в медиадискурсе Германии в условиях подготовки и проведения Чемпионата мира по футболу 2018 года.

Актуальность выявления способов и средств объективации образа России у инокультурного реципиента по мере его знакомства с публикациями о нашей стране и ее жителях обусловлена тем, что желание вступать в тот или иной контакт с субъектом находится в прямой зависимости от характера образа этого субъекта [Гришаева, 2018, с. 40-41].
Следовательно, созданный медиаобраз России в немецкой прессе оказал непосредственное влияние на намерение граждан Германии посетить один или несколько городов-организаторов Чемпионата мира, с тем чтобы на основе личного опыта сформировать собственное представление о стране-хозяйке.

Эмпирическую базу исследования составили материалы электронных версий таких печатных изданий, как «Abendzeitung», «Frankfurter Allgemeine Zeitung», «Zeit», «Bild», «Spiegel», «Süddeutsche Zeitung» и новостного портала «Euronews». C применением метода количественного и качественного тематического контент-анализа изучены 124 новостные статьи, общим объемом 281900 печатных знаков.

\section{Оппозиция «свой - чужой»: семантическое наполнение}

\section{в немецкой и русской лингвокультурах}

В основе восприятия и обработки информации о мире лежит оппозиция «свой - чужой», которая наиболее ярко проявляется при описании международных событий и межкультурного взаимодействия.

«Каждый народ - осознанно, полуосознанно или неосознанно - несет свою идею, свой мир представлений о другом. И поэтому эти естественные и даже необходимые различия своего и чужсого на фоне бесспорно общих задач жизнеобеспечения становятся предлогом, почвой, местом, где начинаются несогласия, различия, споры, ссоры» [Топоров, 1995 , с. 5]. Оппозиция «свой - чужой» семантизирует значимость неких ценностей через противопоставление их антиценностям, а следовательно, отражает философию культур и языков. Данная оппозиция декларирует определенный набор наиболее важных для этноса культурных значений, в том числе и моральнонравственных [Милованова, 2007, с. 24].

В модусе диалогического взаимодействия «чужое» разрывает коммуникативные сети и разрушает конвенции. Итогом встречи может стать ощущение нарастающего раздражения или же, наоборот, обретение душевного равновесия. Подобная двойственность подкрепляется тем, что любой вид взаимодействия с чужими людьми, чужой культурой, чужими взглядами осуществляется не столько 
на осознанно-рациональном, сколько на эмоциональном уровне.

Исторически сложилось так, что люди всегда опасались непонятного, непознанного и незнакомого. Поэтому с точки зрения психологии особого внимания заслуживает тот факт, что опыт встречи с «чужим» всегда проявляется в двух формах: оно вызывает интерес и страх одновременно.

Приведем данные лексикографического анализа лексем, эксплицирующих эту оппозицию в немецком и русском языках:

\section{Duden}

fremd

1. nicht dem eigenen Land oder Volk angehörend, von anderer Herkunft;

2. einem anderen gehörend, nicht die eigene Person, den eigenen Besitz betreffend;

3. unbekannt, nicht vertraut;

4. ungewohnt, nicht zu der Vorstellung, die man von jmdm., etw. hat, passend; andersgeartet.

Большой толковый словарь Кузнецова чужсой

1. Являющийся собственностью другого (других); не имеющий непосредственного отношения к кому-л.; не свой.

2. Не являющийся родиной; не такой, как на родине.

3. Не связанный родственными отношениями; посторонний.

4. Не связанный близкими отношениями с кем-л., не совпадающий по духу, взглядам, интересам; посторонний, далекий.

5. Отчужденный, отрешенный (с. 1486).

В основе значений полисемантичной единицы fremd лежат отношения пространства (далекий, указание на дистанцию), принадлежности (сторонний, другого происхождения), а также его узнаваемости (незнакомый). «Чужое» не может существовать вне «чужого» места, оно пространственно определено [Вальденфельс, 1995, с. 82]. В немецком языке от прилагательного fremd могут быть образованы три существительных: der Fremde - «чужак как пришлый, посторонний человек с другими обычаями и другим языком», die Fremde - «чужбина как далекая, неизвестная сторона», das Fremde - «чужое как принадлежащее другому, нечто далекое по духу». Палитра значений лексемы чужой достаточно широка: от неизвестного, чужестранного и удивительного, до непривычного и постороннего.

Обратимся к словарным дефинициям лексем eigen / свой и сопоставим полученные результаты с результатами анализа семантики лексем fremd / чужой .

\section{Duden}

eigen

1.jmdm. selbst gehörend; einer Sache zugehörend;

2. einer Person zugehörend $u$. für sie typisch, charakteristisch;

3. (veraltend) sonderbar, eigenartig;

4. (nicht $a d v$.) fast übertrieben sorgfältig, genau; penibel: er ist darin sehr eigen.

\section{Болышой толковый словарь Кузнецова свой}

1. Принадлежащий или свойственный себе.

2. Собственный, составляющий имущество или достояние отдельного лица, учреждения.

3. Своеобразный, свойственный только чему-либо одному, данному или единому.

4. Относящийся к себе как члену какого-либо коллектива, какой-либо общности; связанный отношениями родства или общим местом работы, социальным положением, взглядами, вкусами и т. п.

5. Соответствуйщий кому-, чему-либо; подходящий для данных условий, обстоятельств, лиц и т. п. (с. 1162-1163).

С.Ю. Сазонова, исследовавшая концепты, репрезентируемые лексемами eigen / свой в немецкой и русской картинах мира, установила, что эти слова имеют в немецком и русском языках сходное основное значение «собственный, принадлежащий». Различия заключаются в том, что лексема свой не обладает значением «странный, своеобразный, особенный» (cp. у eigen: «sonderbar», «merkwürdig», «eigenartig»). Она употребляется лишь в значении «особый, своеобразный» как свойственный только чему-либо данному [Сазонова, 2010, c. 150-151].

Таким образом, обращение к лексикографическим источникам позволяет нам выделить признаки, на основе которых строится оппозиция «свой - чужой»:

1) eigen / свой и fremd / чужсой обозначают принадлежность, 
2) eigen / свой и fremd / чужсой указывают на вид и образ действий (чужой как своеобразный, вызывающий интерес, непонятный; свой как привычный).

Следует заметить, что понятие «чужой» всегда опосредовано понятием «свой», то есть не является объективной категорией и зависит от интерпретации и установки адресанта. Определяющую роль при трактовке отношений «своих» и «чужих» играют социальный и культурно-исторический контексты.

Руководствуясь точкой зрения П. Канчани о том, что оппозиция «свой - чужой» представляет собой прочную основу реализации коммуникативных стратегий манипулирования в медиапространстве [Канчани, 2007, c. 4], рассмотрим понятие коммуникативной стратегии более подробно.

\section{Понятие коммуникативной стратегии}

В процессе создания любого текста можно условно выделить два этапа:

1) стратегическое планирование, в ходе которого происходит определение содержания и структуры, фокусировка, то есть отбор релевантных пропозиций из когнитивной базы данных и установление риторических связей между ними в зависимости от дискурсивной цели;

2) тактическое использование грамматических и лексических средств для линеаризации содержания, заданного на предыдущем этапе [McKeown, 1987, p. 41].

Следовательно, развертывание каждого текста базируется на определенной коммуникативной стратегии.

Стратегия представления информации это когнитивный механизм, составляющий основу перевода информации о событии, закодированной в ментальных структурах знания, хранящихся в сознании автора, в речевые высказывания, которые формируют содержание текста [Баженова, 2015, с. 17].

С функциональной точки зрения выделяются базовые (семантические, когнитивные) и вспомогательные стратегии, способствующие эффективной организации диалогового взаимодействия, к которым относятся прагматические (коммуникативно-ситуационные), риторические и диалоговые стратегии [Исcepc, 2003, c. 115].
О.С. Иссерс и М.Х. Рахимбергенова предлагают термин «лингвокогнитивная стратегия», то есть целенаправленный выбор языковых средств, который обеспечивает управление процессом умозаключений и трансформацию модели мира адресата. В самом названии отражается взаимообусловленность когнитивных процессов, происходящих в сознании человека, и языковых структур выражения мысли. «Особенность когнитивных стратегий заключается в невозможности эмпирического исследования ментальных процедур, которые большей частью не имеют индикаторов "на поверхности речи” и, следовательно, недоступны для лингвистического анализа. В этом смысле наблюдаемыми являются лингвистические и интеракциональные характеристики, по которым можно определить, как и какими средствами такие цели могут быть достигнуты» [Рахимбергенова, 2007].

Стратегия состоит из отдельных тактических звеньев, тактик, - общих способов представления информации, ориентированных на выполнение более узких коммуникативных задач.

Рассмотрим стратегии и тактики создания образа России как хозяйки ЧМ-2018 в немецкой онлайн-прессе.

\section{Форенизирующие стратегии в медиадискурсе Германии при освещении} Чемпионата мира по футболу в России

По мнению Т.А. ван Дейка при исследовании дискурса пристальное внимание следует уделять тематическим преференциям, актуализирующим отношение к другой, «чужой» стране. Темы чаще всего имеют сознательно контролируемую интенцию и выражают общее содержание ментальных репрезентаций событий, кроме того представляют ту идею или информацию, которую читатели запомнят лучше и надолго [van Dijk, 1996, p. 18].

При анализе новостных статей в сетевой прессе Германии нами были выделены следующие подтемы, раскрывающие образ России в контексте подготовки и проведения Чемпионата мира по футболу: строительство и готовность объектов, безопасность и гостеприимство. 
В актуализации перечисленных подтем ведущей является стратегия алиенации (от лат. alius - другой, отличный из многих). Данная стратегия направлена на присвоение статуса «чужого» описываемым объектам и субъектам. При этом «чужесть» может выражать пространственную, политическую, (этническую) и / или социальную нетождественность.

Стратегия алиенации реализуется посредством тактик противопоставления, угрозы и демонизации.

Тактика противопоставления строится на использовании лексических средств выражения контраста (лексемы с отрицательным и положительным коннотативным значением, частица $d o c h)$ :

(1) Die nächste WM wird in Russland ausgetragen, doch bislang sind nicht alle Stadien fertig (Süddeutsche Zeitung).

(2) Die teuerste Fußball-WM der Geschichte; Eigentlich sollte das Spiel ein sportliches Feuerwerk werden, mit dem Russland das alte Olympiastadion der Sommerspiele von 1980 nach gut vier Jahren Bauzeit wieder eröffnete. Doch der Unmut über die Probleme nach dem Abpfiff überschattet alles! Die Zuschauer mussten mehrere Kilometer zu Fuß gehen, um das Stadion-Gelände zu verlassen. Bei Regen und fünf Grad, im November! (Frankfurter Allgemeine Zeitung. Erster Test für Moskauer Luschniki-Stadion endet im Chaos).

Фееричный праздник спорта, по мнению авторов публикации, превратился в акцию выражения недовольства болельщиков, первый тестовый матч на стадионе «Лужники» завершился хаосом.

В описании архитектуры отдельных стадионов преобладает саркастический тон высказываний:

(3) Wenn es nur überall so pragmatisch zuginge wie in Jekaterinburg, würde die Fußball-WM in Russland als Vorbild für Großveranstaltungen in die Sportgeschichte eingehen. Am östlichsten Austragungsort des Turniers haben sich die Architekten etwas bei einem Gastgeber abgeschaut, der den Tisch auszieht, an dem er sonst allein mit seiner Frau sitzt: Sie haben die Stadionwand durchbrochen und hinter den Toren zusätzliche Tribünen konstruiert, die aus dem eigentlichen Gebäude herausragen. Statt wie sonst 25000 Zuschauer fasst die Arena während der WM mehr als 35000 (Süddeutsche Zeitung. Die teuerste Fußball-WM der Geschichte).

Архитектурное решение выдвижной трибуны на стадионе в Екатеринбурге сравнивается с находчивостью хозяина, который использует раздвижной стол для нагрянувших гостей.

Экспликация агрессивного прагматического потенциала в рамках тактики угрозы прослеживается в следующих заголовках:

(4) Tierschützer schlagen Alarm, FIFA ist alarmiert (Bild);

(5) Rassismus und Fußballgewalt. Hat Russland sein Hooligan-Problem vor der WM im Griff? (Frankfurter Allgemeine Zeitung);

(6) Innenministerium warnt Mitarbeiter vor Ausspähung bei der WM (Zeit).

Языковыми средствами воплощения опасности для граждан Германии выступают иллокутивные глаголы и лексические единицы с превентивной семантикой.

Особенностью немецкого медиадискурса является высокая частотность упоминаний В.В. Путина и, как следствие, отождествление образа президента (на данный момент преимущественно негативного) с образом целой страны. Например:

(7) Putin am Ball: In 100 Tagen beginnt die Fußball-WM (Euronews);

(8) Putins Problemstadion (Spiegel);

(9) WM-Auslosung in Russland. Putins große Fußballshow (Spiegel).

В основе заголовка (7) лежит выражение am Ball sein, то есть «владеть инициативой, быть за рулем» (по аналогии am Steuer sein). В статье, вышедшей под заголовком (8) увеличение сроков строительства стадиона в Самаре объясняется стремлением президента РФ к гигантизму и мировому господству: Mit langer Verspätung eröffnet das letzte Stadion der WM in Russland. Die Arena in Samara ist ein Symbol für Gigantismus und Verschwendung. Viele fragen sich: Was hat das noch mit Fußball zu tun?

Запрет въезда в Россию немецкому журналисту ARD Хайо Зеппельту (Hajo Seppelt) представляется как персональная месть B.В. Путина в связи с причастностью журна- 
листа к расследованию, связанному с нарушением российскими спортсменами антидопинговых правил во время Олимпийских Игр в Сочи:

(10) Das Njet aus dem Kreml zeigt: Die Beteuerungen, dass alle Journalisten frei von der WM berichten können, sind nichts wert. Wer nicht passt, bleibt draußen. Da kann man sich vorstellen, wie lebensgefährlich das Arbeiten für kritische russische Reporter ist (Bild. WM-EINREISEVERBOT FÜR DOPING-EXPERTEN: Putins Rache!).

Переданные посредством транскрибирования русские слова и российские реалии выполняют роль национального маркера. Работа оппозиционного журналиста в России описывается как смертельно опасная.

Отсутствие «прозрачности» данных РУСАДА, а также обвинение в коррумпированности власти при подготовке к ЧМ-2018 находят отражение в заголовке метафорического характера:

(11) Die Welt zu Gast beim Betrüger.

Тактика демонизации нацелена на формирование представления о каком-либо субъекте как существе, которое по своей природе склонно к аморальному и антиобщественному поведению, а также на создание вокруг определенного объекта отрицательного поля смыслов и ассоциаций.

Одним из способов реализации данной тактики выступают сравнения ЧМ по футболу в России с Олимпийскими играми в фашисткой Германии, а президента В.В. Путина с А. Гитлером:

(13) Putin wird die Fußball-WM im Sommer in Russland nutzen, ,wie Hitler die Olympischen Spiele 1936 nutzte" (Bild. Fußball-WM in Russland wie Olympische Spiele 1936).

При создании образа России в медиадискурсе Германии репрезентативной является стратегия экзотизации. Она направлена на репрезентацию субъектов повествования в качестве далеких, причудливых «антиподов», а их поведения, повседневных практик и ритуалов как странных и даже диких. Инструментом реализации данной стратегии становятся тактики аномализации и выделения этноспецифики.
Для тактики аномализации характерно использование приема стереотипизации и сравнений. В новостной статье «Skandal kurz vor WM. Tierquälerei: Bär als Animateur bei russischem Fußballspiel» образ РФ конструируется посредством сравнения сегодняшней России со средневековым государством, когда медведь являлся неотъемлемым атрибутом царского двора:

(12) Ein Braunbär muss das Publikum animieren und den Ball an den Schiedsrichter übergeben. Tierschützer weltweit sind fassungslos. Im Mittelalter waren solche Szenen Normalität: ein Bär mit Maulkorb tritt vor Publikum und muss dieses mit Kunststücken unterhalten. Doch was heutzutage fast überall auf der Welt als Tierquälerei verboten ist, scheint in Russland immer noch Menschen zu begeistern (Abendzeitung).

Для усиления аномальности происходящего в тексте употребляется противительная частица $d o c h$ в сочетании с контекстуальным сравнением, которое можно перевести на русский язык следующим образом «что почти во всем мире запрещено - русских по-прежнему веселит».

Тактика выделения этноспецифики проявляется в подчеркивании этноспецифических черт с целью акцентуации различия. Для ее реализации используются реалии русской культуры и адаптирующие уточнения. Например:

(13) Wieso Wolf? Lernen Sie Zabivaka kennen, das Offizielle Mascottchen der FIFA 2018. Zabivaka bedeutet auf Russisch: Der einen Treffer erzielt; Lecker wie bei Oma! Lernen Sie traditionelle russische Küche kennen! (Zeit. Zabivaka).

С целью привлечения внимания адресата употребляются также грамматические конструкции с формами повелительного наклонения.

Тактика выделения этноспецифики может быть направлена и на создание отрицательного образа страны. В следующем текстовом фрагменте, посвященном поездке иностранцев на российском поезде, осуществляется апелляция к стереотипу «Все русские пьют водку. Русские пьют водку постоянно»:

(14) Erste Lektion von den russischen Mitreisenden: Vor jedem Schnaps ein Trinkspruch. 
Zweite Lektion: Wodka wird nie nach dem Essen getrunken. Vielleicht hören die Russen deshalb nie auf zu essen. Dritte Lektion: Wodka schmeckt immer eklig, aber die Wirkung zählt. Vierte Lektion: Der schlechteste Wodka ist immer der, den man alleine trinkt! (Bild. Abseits in Russland).

Исходя из отрицательной (в редких случаях нейтральной) эмоционально-коннотативной тональности текстов, созданных с использованием стратегий алиенации и экзотизации, обозначим данные стратегии общим термином - форенизирующие стратегии (от англ. foreignization - отчуждение). Заметим, что их перечень может быть расширен в зависимости от целей и материала исследования.

\section{Выводы}

Изучение форм реализации образа как феномена культуры и средства культурной коммуникации необходимо для осмысления современной действительности и для понимания построения мифологем, которые формируют идеологическое общественное поле. Содержательным стержнем медиатекстов о России в контексте Чемпионата мира по футболу выступает оппозиция «свой - чужой», составляющая основу форенизирующих стратегий алиенации и экзотизации. Реализация данных стратегий в немецком медиадискурсе способствовала формированию у болельщиков (читателей) негативных представлений о стране-хозяйке чемпионата (такие представления противоположных тем, которые была призвана сформировать программа «Стратегическое видение» Чемпионата мира в России). Изменить сложившуюся ситуацию способны только критический анализ лингвокогнитивных стратегий конструирования образа страны, а также целенаправленное сравнение нескольких источников информации о стране.

\section{СПИСОК ЛИТЕРАТУРЫ}

Алефиренко Н. Ф., 2016. Медиадискурс и его коммуникативно-прагматическая сущность // Медиалингвистика. № 1 (11). С. 49-57.

Баженова Е. Ю., 2015. Дискурсивные стратегии представления информации в новостных текстах британских СМИ (на материале качественных Интернет-газет) : дис. ... канд. филол. наук / Баженова Екатерина Юрьевна. Благовещенск. $181 \mathrm{c}$.

Вальденфельс Б., 1995. Своя культура и чужая культура. Парадокс науки о «Чужом» / пер. с нем. О. Кубановой // Логос. № 6. С. 77-94.

Гришаева Л. И., 2018. Способы и средства конструирования образа России в немецкоязычном медиапространстве // Формирование образов России и русских в западных дискурсивных практиках XX-XXI веков : материалы Междунар. науч. конф. (19-21 апреля 2018 г.). Воронеж : Научная книга. С. 40-49.

Добросклонская Т. Г., 2012. Язык политического медиадискурса Великобритании и США // Язык СМИ и политика / под ред. Г. Я. Солганика. М. : Изд-во Моск. ун-та. С. 741-784.

Желтухина М. Р., 2017. Медиатекст: дискурсивное проявление и коммуникативная практика в суггестивном аспекте // Текст: дискурсивное проявление и коммуникативная практика : сб. науч. ст. в честь юбилея д-ра филол. наук, проф. Л. Г. Викуловой / под общ. ред. Е. Г. Таревой. М. : МГПУ ; «Языки народов мира». C. $138-148$.

Иссерс О. С., 2003. Коммуникативные стратегии и тактики русской речи. М. : УРСС. 284 с.

Канчани П., 2007. Оппозиция «свой - чужой» как прагматическая доминанта политического дискурса : дис. ... канд. филол. наук. Москва. 260 с.

Маркузе Г., 1994. Одномерный человек. Исследование идеологии развитого индустриального общества. М. : Рефл-бук. 368 с.

Милованова М. В., 2007. Категория посессивности в русском и немецком языках в лингвокультурологическом освещении. Волгоград : Волгогр. науч. изд-во. 408 с.

Рахимбергенова М. Х., 2007. Оценочные стратегии в создании образа этнически «Чужого»на страницах Российской прессы // Юрислингвистика. № 8. С. 244-250. URL: https://cyberleninka.ru/article/n/ otsen ochnye-strategii-v-sozdanii-obrazaetnicheski-chuzhogo-na-stranitsah-rossiyskoypressy-1 (дата обращения: 20.05.2018).

Сазонова С. Ю., 2010. Концепт «свой» в русской и немецкой языковой картине мира // Вестник Амурского государственного университета. №48. C. 147-151.

Топоров В. Н., 1995. Миф. Ритуал. Символ. Образ: исследования в области мифопоэтического. Избранное. М. : «Прогресс»-«Культура». 624 с.

Dijk T. A. van, 1996. Discourse, racism and ideology. La Laguna (Spain) : RCEI Ediciones. 63 p.

McKeown K. R., 1987. Discourse strategies for generated natural-language text. New York : Columbia Univ. 41 p. 


\section{ИСТОЧНИКИ И СЛОВАРИ}

Большой толковый словарь Кузнецова - Большой толковый словарь русского языка / гл. ред. С. А. Кузнецов. СПб. : Иоринт, 2004. 1536 с.

Abendzeitung - Abendzeitung. URL: https://www. abendzeitung-muenchen.de.

Bild-Bild. URL: https://www.bild.de.

Duden - Duden. Das Bedeutungswörterbuch. Mannheim : Dudenverlag, 2010.1152 p.

Euronews - Euronews. URL: https://www.ole. euronews.com.

Frankfurter Allgemeine Zeitung - Frankfurter Allgemeine Zeitung. URL: https://www.faz.net.

Spiegel-Spiegel. URL: http://www.spiegel.de.

Süddeutsche Zeitung - Süddeutsche Zeitung. URL: https://www.sueddeutsche.de/.

Zeit-Zeit. URL: https://www.zeit.de.

\section{REFERENCES}

Alefirenko N.F., 2016. Media discourse and its communicative and pragmatic entity. Medialingvistika [Media Linguistics], no. 1 (11), pp. 49-57.

Bazhenova E.Yu., 2015. Discursive strategies for presenting information in the news texts of British mass media (based on high-quality Internet newspapers). Cand. philol. sci. diss. Blagoveshchensk. $181 \mathrm{p}$.

Valdenfels B., 1995. Own culture and foreign culture. The paradox about 'Alien'. Logos, no. 6, pp. 77-94.

Grishaeva L.I., 2018. The ways and means of constructing the image of Russia in the Germanspeaking media space. Formirovanie obrazov Rossii i russkikh $v$ zapadnykh diskursivnykh praktikakh XX-XXI vekov: Materialy Mezhdunar. nauch. konf. (19-21 aprelya 2018 g.). Voronezh, Nauchnaya kniga Publ., pp. 40-49.

Dobrosklonskaya T.G., 2012. The language of the political media discourse of the United Kingdom and the United States. Solganik G.Ya., ed. Yazyk SMI $i$ politika. Moscow, MGU Publ., pp. 741-784.

Zheltukhina M.R., 2017. Media text: discursive manifestation and communicative practice in the suggestive aspect. Tareva E.G., ed. Tekst: diskursivnoe proyavlenie i kommunikativnaya praktika: sb. nauch. st. $v$ chest yubileya d.f.n., prof. L.G. Vikulovoy. Moscow, Yazyki narodov mira Publ., pp. 138-148.

Issers O.S., 2003. Communicative strategies and tactics of Russian speakers. Moscow, URSS Publ. 284 p.

Kanchani P., 2007. Opposition 'own - alien' as a pragmatic dominant of political discourse. Cand. of philol. sci. diss. Moscow. 260 p.

Markuze G., 1994. One-dimensional man: studies in the ideology of advanced industrial society. Moscow, Refl book Publ. 368 p.

Milovanova M.V., 2007. The category of possession in Russian and German in terms of linguocultorology. Volgograd, Volgogradskoe nauchnoe izd-vo. $408 \mathrm{p}$.

Rakhimbergenova M.Kh., 2007. Evaluation strategies in creating the image of ethnically 'Alien' in the Russian press. Yurislingvistika, no. 8, pp. 244250. URL: http: //cyberleninka.ru/article/n/ otsen ochnye-strategii-v-sozdanii-obrazaetnicheski-chuzhogo-na-stranitsah-rossiyskoypressy-1. (accessed 20 May 2018).

Sazonova S.Yu., 2010. The Concept 'own' in the Russian and German worldview. Vestnik Amurskogo gosudarstvennogo universiteta, no. 48, pp. 147-151.

Toporov V.N., 1995. Myth. Ritual. Symbol. Image: Research in the field of mythopoietics. Moscow, Progress Publ. 624 p.

Dijk T. A. van, 1996. Discourse, racism and ideology. La Laguna, RCEI Ediciones. 63 p.

McKeown K. R., 1987. Discourse strategies for generated natural-language text. New York, Columbia Univ. 41 p.

\section{SOURCES AND DICTIONARIES}

Kuznetsov S.A., ed. 2004. Big explanatory dictionary of the Russian language. Saint Petersburg, Iorint Publ. $1536 \mathrm{p}$.

Abendzeitung. URL: https://www. abendzeitungmuenchen.de.

Bild. URL: https://www.bild.de.

Duden. Das Bedeutungswörterbuch. Mannheim, Dudenverlag, 2010. $1152 \mathrm{p}$.

Euronews. URL: https://www.ole. euronews.com.

Frankfurter Allgemeine Zeitung. URL: https://www. faz.net.

Spiegel. URL: http://www.spiegel.de.

Süddeutsche Zeitung. URL: https://www. sueddeutsche.de/.

Zeit. URL: https://www.zeit.de. 


\section{Information about the Authors}

Marina V. Milovanova, Doctor of Sciences (Philology), Professor, Department of Russian Philology and Journalism, Volgograd State University, Prosp. Universitetsky, 100, 400062 Volgograd, Russia, mv_milovanova@volsu.ru,https://orcid.org/0000-0002-6198-6972

Marina Yu. Svinkina, Candidate of Sciences (Philology), Associate Professor of Department of Translation Studies, Volgograd State University, Prosp. Universitetsky, 100, 400062 Volgograd, Russia, svinkina@volsu.ru, https://orcid.org/0000-0001-5378-8848

\section{Информация об авторах}

Марина Васильевна Милованова, доктор филологических наук, профессор, профессор кафедры русской филологии и журналистики, Волгоградский государственный университет, просп. Университетский, 100, 400062 г. Волгоград, Россия, mv_milovanova@volsu.ru, https:// orcid.org/0000-0002-6198-6972

Марина Юрьевна Свинкина, кандидат филологических наук, ассистент кафедры теории и практики перевода, Волгоградский государственный университет, просп. Университетский, 100, 400062 г. Волгоград, Россия, svinkina@volsu.ru, https://orcid.org/0000-0001-5378-8848 